\title{
Um outro de quem se fala: \\ alteridade e autoria em $A$ pessoa é para o que nasce
}

Mariana Duccini ${ }^{1}$

Resumo: Tendo como objeto de análise o documentário A pessoa é para o que nasce (2005), dirigido por Roberto Berliner, o artigo circunscreve a constituição de uma instância autoral segundo princípios discursivos. Por meio dos conceitos de cenas da enunciação e de paratopia de autor, de Dominique Maingueneau (2006), serão consideradas as estratégias discursivas que operam de forma a legitimar uma posição autoral por meio da estabilização de procedimentos que articulam efeitos de autoridade e de autorização a uma instância enunciativa que empreende a criação artística.

Palavras-chave: autoria, discurso, documentário, cenas enunciativas, paratopia.

\begin{abstract}
This article proposes a reflection on the constitution of the authorship according to a discursive overview in Roberto Berliner's Brazilian documentary A pessoa é para o que nasce (2005). Maingueneau's concepts about enunciative scenes and paratopic position of the enunciator lead us to consider the strategies which legitimate such statements of the authorship. In this way, we investigate the procedures that articulate effects of authority and accreditation towards an enunciative instance that undertakes artistic creations.
\end{abstract}

Keywords: authorship, discourse, documentary, enunciative scenes, paratopy.

Para além de uma representação pretensamente imediata de um dado 
da realidade, o exercício do documentário cinematográfico não se faz em vista de um alhures do mundo. Materialidade discursiva, o documentário releva os tensionamentos de um estar no mundo, em que as posições subjetivas, as disputas por sentidos e as vontades de verdade (FOUCAULT, 2002) são continuamente encenadas e reencenadas - em um movimento de legitimação -, em vista da própria dinâmica das práticas sociais. Emergem, assim, o papel e o valor de uma verdade situada: a despeito da perspectiva "instrumentalizante" de objetividade, haveria um ponto de vista a ser documentado.

É, pois, em termos de uma autorização que esse ponto de vista se estrutura como uma instância autoral: conferindo às materialidades textuais alguma unidade, segundo um princípio de organização, e assumindo responsabilidade jurídica em relação àquilo que é dito (FOUCAULT, 1994), tal instância conforma-se a um lugar reconhecido, legitimado por uma comunidade discursiva. A ocupação de um posicionamento, em tais parâmetros, deve operacionalizar determinadas habilidades "inscritivas" segundo as quais um autor se autoriza: dá a ver, a si e ao público, os sinais de sua validação.

Em tal perspectiva, só se torna plausível a concepção do lugar-autor no viés das dinâmicas sociais que mobilizam a ordem dos discursos. Por meio da ativação de memórias, as práticas estabelecidas são reiteradas, de acordo com a formulação de Maingueneau (2006) acerca de ritos genéticos: as atividades protocolares, cristalizadas em cada momento histórico e em cada espaço da vida social, segundo as quais se produz, legitimamente, um enunciado.

Para determinar quem tem o direito de enunciar, um posicionamento literário define à sua própria maneira o que é um autor legítimo. Cada autor se orienta em função da autoridade que tem condições de adquirir, dadas as suas conquistas e a trajetória que concebe a partir delas num dado estado do campo (MAINGUENEAU, 2006, p. 152).

À luz das ponderações desse teórico sobre o campo específico da literatura, é possível pensar em um princípio de generalização, concernente à própria lógica dos discursos, na referida ocupação de um posicionamento: esta qualifica 
de antemão os parâmetros de uma autoridade enunciativa. Na dinâmica de estabelecimento de um autor, a autorização necessária ao empreendimento responde pela materialização de estratégias discursivas que explicitem a exacerbação da condição interlocutória.

O deslocamento, assim, em direção a um outro (o que é, em si, parâmetro constitutivo das práticas discursivas, uma vez que não há meios de assumir um posicionamento enunciativo a não ser em relação a um posicionamento outro, em um viés de "responsividade" estrutural) não se faz de maneira aleatória. Mobilizam-se, para tanto, repertórios, memórias, regiões específicas dentro do universo interdiscursivo. O lugar do autor, conforme será debatido adiante, tem como especificidade uma condição movente, que tende ao deslocamento: estrutura-se, de maneira explícita, sempre "em relação a". As formas de gerência dessa mobilidade radical, respondem, pois, à condição criativa que legitima um lugar-autor.

Conjuntamente à construção de um posicionamento autoral, torna-se relevante a abordagem do fenômeno em vista da situação de comunicação - e não, isoladamente, da ênfase exclusiva em um dos actantes do processo. Isso leva em conta a prerrogativa de considerar as formas de estruturação segundo as quais um dado do mundo é convertido em uma cena de fala correspondente (ou ainda, o movimento pelo qual uma cena de fala diz respeito a um dado do mundo). A mobilização dessas cenas - espaços validados em nome das práticas de discurso correntes em uma sociedade - advém também como eixo legitimador de uma função autoral, uma vez que opera remetendo a procedimentos institucionalizados no âmbito social.

Os parâmetros aqui apresentados (a conformação particular de um enunciador segundo uma tópica fundada na dinâmica dos entrelugares e a colocação em cena de formas, discursivamente validadas, que remetem a dados do mundo) respondem, segundo as formulações de Maingueneau (2006), a duas especificidades do exercício da autoria: a paratopia como condição 
criadora e as cenas de enunciação como formas protocolares que atualizam os conteúdos mobilizados em todo ato de comunicação.

Com base nesses conceitos, pretende-se analisar de que forma é construído/legitimado o lugar-autor no documentário cinematográfico $A$ pessoa é para o que nasce (2005), dirigido por Roberto Berliner. Tendo como protagonistas as irmãs Maria, Regina e Conceição Barbosa, o filme busca retratar de que forma as limitações físicas das personagens (elas são cegas) singularizam suas formas de relação com o cotidiano (as três sobrevivem à custa de esmolas, tocando ganzá nas ruas do município paraibano de Campina Grande), além de explicitar a mudança causada pela produção e pela difusão do próprio documentário na vida das três mulheres.

Nesse âmbito, tornam-se emblemáticas as investidas autorreflexivas presentes no objeto de análise (mostração de câmera, alusões claras ao estatuto do filme, formas de negociação com as personagens, e recorrência a outros campos legitimados das práticas sociais, como a instituição jornalística), na medida em que "figurativizam" uma realidade que se constrói como artefato, endossando o estatuto do documentário (o que é viabilizado pelos modos de cenografar propostos pelo enunciador, que aqui se autorizam em termos de uma configuração autoral).

As estratégias discursivas consideradas no desenvolvimento da análise articulam efeitos de sentido que, respaldando-se em vetores de cenas validadas, propõem uma calibragem da tensão identidade-alteridade (cujos polos, aqui, referem-se à instância enunciadora e às três protagonistas do documentário), de maneira a garantir uma articulação fundada em uma dissimetria radical - que, entretanto, garante legitimidade ao lugar-autor. Uma relação que muito raramente se expressa em termos simétricos inviabilizando a reversibilidade total entre quem diz e aqueles sobre quem se diz - faz emergir, de través, as disposições de autoridade e de autorização necessárias à sedimentação do autor. 
Com vistas a operacionalizar a análise, foram selecionados excertos do documentário que apresentassem, em termos de materializações discursivas, construções relevantes para ilustrar as problematizações aqui circunscritas. Dessa maneira, chegou-se a uma composição de cenas editadas cuja ordem de exibição (em termos de cronologia) segue a do documentário original. Totalizando 8 minutos e 49 segundos, essa sequência é iniciada por meio de um plano em panorâmica da cidade de Campina Grande. O som correspondente é extradiegético (não coincidente com os ruídos ambientes correspondentes à captação das imagens), referindo-se a uma locução de um programa radiofônico jornalístico bastante conhecido na Paraíba, o Matutino Borborema. A voz em off do narrador explicita o fato de as irmãs Maria, Regina e Conceição (a quem se alude como "as ceguinhas de Campina Grande") serem protagonistas do filme, tornando-se "estrelas de cinema" (essa expressão, com efeito, será repetida por oito vezes - e por diferentes personagens -, no intervalo total de 8 minutos e 49 segundos, relativo à sequência editada para esta análise).

As tomadas seguintes mostram uma afluência de jornalistas à casa das irmãs, ora retratadas como celebridades. Repete-se a alusão ao fato de terem se transformado em "estrelas de cinema" - os microfones e as câmeras de TV, exibidos com destaque, convertem-se em índices de remissão a uma cena enunciativa amplamente validada: a do exercício do jornalismo segundo seus valores de produção (e, posteriormente, de difusão) de notícias a partir de acontecimentos marcados pela recentidade (ou ainda pela novidade de abordagens incomuns).

Ao pensarmos na cenografia mobilizada nesse excerto (o modo pelo qual se institui a cena de enunciação que legitima um discurso), depreende-se uma composição baseada na hibridização de cenas estabilizadas: a do próprio documentário - que pode ser interpretada como cena englobante, uma vez que se refere ao tipo de discurso posto em marcha, um patamar em que o leitor se situa, segundo práticas consagradas, para interpretar aquilo que a ele se apresenta; a do jornalismo (já discutida); e a do star system, o modelo 
cinematográfico hollywoodiano tradicional, em que uma das expressões mais características é a da mobilização de um imaginário social acerca do modo de vida de seus atores e atrizes. Emerge, então, um parâmetro que se repete em vários momentos de $A$ pessoa é para o que nasce: uma espetacularização da miséria (tanto física quanto social), que, paradoxalmente, confere à instância autoral um certo caráter salvacionista, redentor - o que se reitera, como efeito de sentido, tanto por meio da fala da personagem Maria, no mesmo segmento ("Deus escolheu um pra vir pra cá contar a nossa história"), quanto por meio de uma indicação paratextual, em um dos textos de divulgação do documentário: "O filme que mudou a vida de três irmãs. Três mulheres que vão mudar a sua maneira de ver o mundo".

A continuação da cena mostra as personagens em um cenário de comunhão com a natureza: ora deitadas na relva, ora movimentando-se entre árvores e arbustos, circunstância em que se destaca a iluminação por raios solares. Estrutura-se, pois, aquilo a que Maingueneau (2006, p. 99-100) alude como uma natureza lendária, o resto de um mundo ancestral, aquilo que sobra em uma sociedade autodeterminada pelas matrizes da industrialização. Em sua condição afim à natureza primitiva, as "ceguinhas" são "figurativizadas" de acordo com um significado ambivalente: o sagrado da comunhão com o universo e o maldito da barbárie, da deformação. Em termos de uma gramática da estética fílmica, tal efeito de sentido é alcançado pelo emprego de lentes grande-angulares, que capturam close-ups dos rostos das personagens. Sob o ponto de vista técnico, tal empreendimento, ao explicitar detalhes das personagens, acentua os efeitos da pobreza e do desamparo (a ausência de dentes, as peles bastante vincadas, o desbotamento dos globos oculares, os cabelos em completo desalinho).

O caráter grotesco dessas tomadas mobiliza uma memória, aludindo, de maneira indireta, aos espetáculos de bizarrices outrora comuns em feiras e em certos ambientes circenses - efeito que se potencializa pela fala da personagem Conceição: "O cinema, quanto mais animado, melhor", acompanhada por uma música dissonante. A finalização dessa cena traz as três irmãs manipulando, 
evidentemente às cegas, uma câmera de cinema - alienadas da real dimensão que aquilo assumiria em suas existências cotidianas; um saber sobre o sujeito que, no entanto, é alheio ao próprio sujeito (FOUCAULT, 1979).

A sequência segue mobilizando um efeito de sentido aparentemente polêmico, pela colocação em cena de um estatuto, em tese, desestabilizador. Uma das personagens pergunta diretamente ao realizador (Roberto Berliner) "de quem havia partido a ideia daquele documentário", afirmando, ainda, que muitas pessoas dizem que o intuito do filme seria apenas o de ganhar dinheiro explorando as histórias delas (das personagens). Tal referencial catalisa, ainda outra vez, a construção de uma cenografia pronta a reiterar a legitimidade ética do discurso fílmico - e, consequentemente, a da instância autoral. Após a fala de Maria ("O que eu quero é ficar conhecida"), a materialidade imagética é orientada a partir de um movimento ascendente da câmera, que mostra as três personagens, no topo de um monte, de baixo para cima (o que na sintagmática fílmica/fotográfica recebe a denominação de contre-plongée). O efeito de sentido mobilizado por essa construção é o de atribuir uma ideia de poder e triunfo às personagens - algo que é referendado pela composição musical, de tom marcadamente épico, acompanhando tal movimento de câmera. Uma conjugação dessas emergências discursivas articula, em termos de semântica global, o efeito de as personagens passarem (graças ao documentário) por um processo de redenção que as conduziria "ao topo do mundo". Em termos de validação cênica, no já referido star system hollywoodiano, tal acepção chega mesmo a ser estereotípica, assumindo uma autonomização que a torna passível de ser reinvestida em outras cenas estabilizadas (MAINGUENEAU, 2004, p. 92).

Ainda sob o sentido metafórico de "estar no topo", os planos finais da sequência trazem as "ceguinhas" de Campina Grande alçadas ao estrelato, por meio da apresentação delas durante o PercPam (Panorama Percussivo Mundial), em 2000, na concha acústica do Teatro Castro Alves, em Salvador. Imagens captadas nos camarins mostram o encontro entre elas e os reconhecidos músicos Naná Vasconcelos e Gilberto Gil (que assumiria, anos depois, o cargo 
de Ministro da Cultura do governo Lula).

Expressando uma consideração ao mesmo tempo embevecida e condescendente para com às irmãs, os músicos falam, de maneira explícita, sobre o papel fundamental do realizador do documentário, Roberto Berliner, na trajetória delas. Nesse momento, a instância autoral emerge, de maneira clara, segundo uma dimensão paratópica que a legitima pela construção de um lugar que articula os vieses de pessoa, inscritor e escritor (aqui identificado ao papel de diretor/realizador do documentário).

\section{O lugar-autor: tópica de um assentamento inviável}

Uma das condições a engendrarem o lugar-autor refere-se a uma gestão de forças de identidade e de dispersão, no intuito de co-ordenar unidades discursivas, em nome de um princípio de organização. Um posicionamento autoral - assim como qualquer outro posicionamento enunciativo - mobiliza, via cenas enunciativas, regiões específicas do interdiscurso (condição de base de toda prática discursiva), tendo em consideração imagens estabilizadas (expectativas) em termos de uma alteridade (identificada à comunidade na qual determinada prática de discurso emerge e vai à circulação).

No que tange à especificidade da autoria, nota-se uma exacerbação da condição interlocutória: o autor só emerge como tal em virtude de um deslocamento explícito rumo a um outro. As formas de reconhecimento - a um só termo, de institucionalização - acerca do que é ser um autor, naturalmente, são variáveis a cada momento histórico. Um projeto de autoria, em todo caso, sempre será modulado por ritos genéticos que respaldam a construção de uma imagem, pregnante no corpo social, autossuficiente para mobilizar investimentos criativos. Esse exercício, portanto, leva em consideração gestos prototípicos, protocolos a serem seguidos em relação a essa alteridade.

Para além de uma unidade compacta, entretanto, o lugar-autor desenhase em conformidade a um entrelaçamento de posições, de natureza paratópica 
(MAINGUENEAU, 2006), que faz desse posicionamento uma noção movente, dinâmica. É na intersecção entre a pessoa (um determinado modo de ser, de estar no mundo, ainda que não de forma exclusivamente empírica), o inscritor (agente da enunciação, que põe em marcha a cena enunciativa, em que se delineia uma atuação testemunhal do sujeito) e o escritor (instância institucionalizada, respondente a um feixe de representações sociais sobre o sujeito criador) que se amalgama uma função de autor.

Em A pessoa é para o que nasce, a calibragem paratópica vem estruturar um entrelugar do qual a função-autor retira sua legitimidade. Ainda à luz de Maingueneau, sublinhamos que a paratopia não é um dado a priori, mas advém como própria condição criativa de obras reconhecidas no espectro mais amplo dos discursos. O documentário explicita esse posicionamento deslocado, por meio da instauração das instâncias de pessoa, inscritor e escritor - cujas existências só podem ser viabilizadas por uma dependência mútua, estruturante. É nesse âmbito que a categoria de pessoa alude a um modo de ser, de se apresentar, que, solidariamente, endossa as categorias de inscritor e de escritor (ao passo em que é por elas também endossada), na gênese da autoria.

A pessoa Roberto Berliner é erigida no filme de maneira a (dis)simular uma relação de horizontalidade hierárquica com as três protagonistas, potencializando um efeito de sentido que visa demonstrar uma reversibilidade equânime entre eles. Em diferentes momentos da película, são expostas situações de alguma intimidade, em que o realizador frequenta a casa das personagens, suscita momentos em que elas expõem histórias algo delicadas ou constrangedoras e chega mesmo a filmá-las nuas, tomando banho de mar (em uma das últimas sequências do documentário).

$\mathrm{Na}$ perspectiva de inscritor, respondendo pela marcha da enunciação, o realizador institui uma cena enunciativa validada, cuja legitimidade advém tanto de sua autorização autoral quanto da estabilização, via prática social, dos modos de cenografar o enredo e o próprio estatuto do documentário, 
conforme será analisado adiante. É nesse mesmo âmbito que o diretor é várias vezes de maneira explícita - legitimado como o responsável pelo filme, em que se sublinhe o aspecto valorativo eufórico relativo a seu trabalho de inscrição: sustentando uma representação da categoria de escritor, ele é visto como aquele que retirou da obscuridade as três personagens, possibilitando a elas uma existência um pouco menos miserável, ainda que, para tanto, desse forma a "figurativizações" de caráter redutor e estereotipado.

A dimensão de escritor, compondo a articulação tríplice do posicionamento de autor, alude a um sujeito que desenvolve uma trajetória em termos institucionais, ao assumir de maneira legítima determinado lugar no campo social em que atua (BOURDIEU, 2007). O escritor (que nesta análise é associado à dimensão do documentarista) responde pelos ritos legítimos, ao mesmo tempo em que é por meio deles engendrado.

A dispersão intrínseca a uma condição paratópica converte-se na própria condição da autoria. Ao serem observadas as formas de estruturação desse lugar em A pessoa é para o que nasce, emergem efeitos de sentido que atribuem ao autor a gerência de um duplo estatuto: por um lado, o exercício meramente especular (dada a mostração gratuita das dificuldades, dos constrangimentos e das dificuldades das protagonistas); por outro, uma atitude indulgente, que conferiria ao autor - e, por extensão, à imagem de uma prática documentária um valor pretensamente salvacionista, na relação com as mesmas personagens. Tal ambivalência é depreendida já no título do filme, que expressa tanto o caráter de predestinação do autor/documentarista, "enviado por Deus para contar a história das ceguinhas", em uma recomposição da fala de Maria Barbosa, quanto o determinismo implícito nos modos de narrar histórias sobre aquelas pessoas que são (só) para o que nascem. 
A dinâmica da autoria, em vista das coordenadas de uma situação de comunicação, deve também ser pensada à luz de um gênero de discurso princípio de conformação de feixes de enunciados que se tornam estáveis à medida que se institucionalizam pelas práticas sociais. Tais atividades condicionam conjuntos de procedimentos que, tão heterogêneos quanto as próprias práticas, modulam os atos de comunicação.

Como o discurso só é acessível por meio de textos de naturezas diversas - donde a célebre formulação de Maingueneau (2004, p. 85) segundo a qual "o texto é o rastro deixado por um discurso, em que a fala é encenada" - , o gênero há de ser considerado em um movimento de mobilização e de recorrência a cenografias estáveis (modos prototípicos de colocar em cena uma situação comunicativa). O princípio de validação de enunciados intrínseco à noção de cena da enunciação só pode ser compreendido na dinâmica de uma articulação entre a cena englobante, a cena genérica e a cenografia.

Identificada como um "tipo de discurso", a cena englobante diz respeito a um patamar em que o interlocutor deve situar o discurso para apreendê-lo e interpretá-lo, segundo as conformações elementares a sua estruturação. É por meio da cena englobante que uma disposição prévia de leitura é ativada. Em termos de filmes documentários, esse patamar reúne materializações programáticas afins àquilo que Odin (1984) qualifica como uma leitura "documentarizante" (em contraste com uma leitura "fictivizante"), por meio de marcas textuais específicas, que catalisam índices de referencialidade, denotações paratextuais (legendas indicativas, indicação de personagens a representarem as ações que efetivamente exercem no cotidiano), formas de circulação do texto fílmico e qualificação em vista de interlocutores específicos - propondo, em suma, um rastreamento de cenas validadas, a fim de mobilizálas em uma cenografia específica. A cena englobante dá a ver um ponto de vista suficientemente legítimo para ser documentado.

Quanto à cena genérica, viabiliza-se a efetivação da cena englobante, 
em vista da ordenação de gêneros particulares de discurso - é dessa maneira, por exemplo, que a cena genérica "aula" é uma das materializações da cena englobante "discurso educacional/instrucional". A se considerar A pessoa é para o que nasce, é pertinente pensar em termos da filiação desse filme a uma tradição documentária que se torna exemplar, entre os anos 1950 e 1960, sobretudo com as obras do cineasta Jean Rouch. Ocupada em problematizar - estatuto da objetividade no campo do documentário, essa tradição, generalizada sob a denominação de cinema-verdade, destina ao documentário a tarefa de expor uma verdade que só emerge em vista do filme, na gênese de sua enunciação: "o cinema-verdade não é a verdade do cinema, é a verdade no cinema" (ROUCH apud COLLEN, 1995). Tal distinção, em nome de uma verdade situada, é expressa, principalmente, em termos da preocupação em se configurar um "outro de quem se fala": as personagens do documentário. Não se trata de dissimular uma evidência - e mesmo uma condição elementar dessa prática, um inegável poder exercido por aquele que empunha, empírica ou figuradamente, a câmera (FREIRE, 2007), mas de dar a ver, como elemento estrutural do cinema-verdade, essa dissimetria constitutiva.

É nesse viés que o documentário de Berliner mostra-se paradoxalmente inovador, em termos estéticos, e conservador, em termos de posicionamento enunciativo global. Os já referidos investimentos autorreflexivos presentes no filme dão conta de desarticular radicalmente uma pretensa objetividade cuja tradição pode ser remontada mesmo ao final do século 19 , com a estabilização das práticas da fotografia e do cinema, recobertas por formulações imaginárias que aludem a uma "captação imediata do mundo". A verdade situada, a todo tempo reposta em $A$ pessoa é para o que nasce, remete ao interlocutor a pertinência e as especificidades do gênero documentário nos termos de um cinema-verdade.

Ocorre, entretanto, que uma das mais expressivas derivações do cinemaverdade é o intuito de apreender o outro em sua irredutibilidade, não em termos de um empirismo ingênuo, mas da própria dinâmica, intrínseca à prática, que o 
converte em personagem pela ativação de uma mise-en-scène de si: "Colocar-se à escuta das falas das pessoas, aquelas que nos propomos a filmar, no momento mesmo da filmagem, escutá-las, sugerir-Ihes que se coloquem a partir disso, do fato bem simples de que há escuta. A câmera escuta. Que eles atuem, então, a partir de suas próprias palavras" (COMOLLI, 2008, p. 55).

A mobilização de cenografias estabilizadas, motor da articulação de um quadro cênico (conjugação da cena englobante com as cenas genéricas), por meio de cenas validadas graças à dinâmica das trocas sociais, legitima, progressivamente, a enunciação que sustenta tanto o estatuto do documentário quanto a posição do autor. Cristalizadas na memória coletiva, tais cenas validadas amalgamam as plataformas culturais que sustentam disposições valorativas de cada tempo e de cada lugar. A formulação de Moscovici (2003) acerca das estratificações sociais dimensiona essa problemática. Bases que determinam os sentidos das práticas sociais (sendo mutáveis em vista de diferentes tempos e lugares), as estratificações operacionalizam efeitos de constrangimento dos discursos, na medida em que a dinâmica própria a elas diz respeito à busca de filiações das narrativas a campos estabilizados. Tal ordem de reiteração viabiliza um duplo movimento: a legitimação de certos discursos recorrentes (pela frequência com que rebatem no campo), assim como a própria constituição do campo.

A se ter em vista o espaço de prática do cinema, aqui entendido como meio institucionalizado, torna-se interessante dimensionar o gênero documentário sob a ótica da tensão identidade-alteridade. Cenografando essa relação, o lugarautor, que tanto propõe uma organização textual-discursiva quanto responde pela unidade da obra, no documentário analisado, mobiliza cenas amplamente validadas: o papel assistencialista/redentor por parte daqueles que exercem o poder em relações socialmente dissimétricas; a "figurativização domesticada" por parte daqueles que se mostram mais desfavorecidos na mesma relação; uma estetização da miséria em uma sociedade conformada à visibilidade 
indiscriminada; a diluição das fronteiras entre espaço público e privado.

A disposição de autoridade/autorização que possibilita a emergência autoral em A pessoa é para o que nasce, portanto, mobiliza vetores de ordem imaginária, que, apesar de recorrerem a cenas validadas que programam reações impulsionadas pelo lirismo, repõemuma vontade de verdade afim à manutenção de determinados estereótipos relativos a conformações sociais bastante conservadoras. 
BAKHTIN, M. "Os gêneros do discurso". In: Estética da criação verbal. Tradução de Paulo Bezerra. São Paulo: Martins Fontes, 2003.

BOURDIEU, P. O poder simbólico. Rio de Janeiro: Bertrand Brasil, 2007.

COLLEN, J.-P. Entrevista: "Jean Rouch, 54 anos sem tripé". In: Cadernos de Antropologia e Imagem, Rio de Janeiro: UERJ, v. 1, 1995.

COMOLLI, J. L. Ver e poder: a inocência perdida: cinema, televisão, ficção, documentário. Belo Horizonte: UFMG, 2008.

DA-RIN, S. Espelho partido: tradição e transformação do documentário. São Paulo: Azougue Editorial, 2006.

FREIRE, M. "Jean Rouch e a invenção do Outro no documentário". In: Revista Digital de Cinema Documentário: documentário e antropologia, n. 3, dez. 2007. Disponível em: <http://www.doc.ubi.pt/03/doc03.pdf\#page=61>.

FOUCAULT, M. "Qu'est-ce qu'un auteur?" In: Dits et écrits: tome 1. Paris: Gallimard, 1994. Microfísica do poder. Rio de Janeiro: Graal, 1979. . A ordem do discurso. São Paulo: Edições Loyola, 2002. . A verdade e as formas jurídicas. Rio de Janeiro: Nau Editora, 2005.

GOMES, M. R. Comunicação e identificação: ressonâncias no jornalismo. São Paulo: Ateliê Editorial, 2008.

MAINGUeneAU, D. Análise de textos de comunicação. São Paulo: Cortez, 2004. . Discurso literário. São Paulo: Contexto, 2006.

."A propósito do ethos". In: MOTTA, A. R.; SALGADO, L. (Org.). Ethos discursivo. São Paulo: Contexto, 2008.

MORIN, E. "Chronicle of a Film". In: ROUCH, J.; FELD, S. Cine-ethnography/Jean Rouch. Minneapolis: University of Minnesota Press, 2003.

MOSCOVICI, S. Representações sociais: investigações em psicologia social. Petrópolis: Vozes, 2003.

NICHOLS, B. Introdução ao documentário. Campinas: Papirus, 2005. 
ODIN, R. "Film documentaire, lecture documentarisante". In: ODIN, R.; LYANT, J.C. Cinémas et réalites. Saint-Etienne: Université de Saint-Etienne, 1984.

PÊCHEUX, M. O Discurso: estrutura ou acontecimento. Campinas: Pontes, 2006.

POSSENTI, S. Os limites do discurso: ensaios sobre discurso e sujeito. Curitiba: Criar Edições, 2002.

\section{Filmografia}

A pessoa é para o que nasce

Direção: Roberto Berliner

Roteiro: Maurício Lissovski

Produtora: TV Zero

Ano: 2005

1 Doutoranda em Ciências da Comunicação pela ECA-USP. Pesquisadora-membro de MidiAto - Grupo de Estudos de Linguagem: Práticas Midiáticas (ECA-USP). Foi professora colaboradora da Pós-Graduação em Estudos da Linguagem, da Universidade de Mogi das Cruzes e colaboradora do Comunique-se Comunicação Corporativa Ltda. 